\title{
The Use of Electrochemical Techniques to Characterize Wet Steam Environments
}

\author{
Bruce W. Bussert, John A. Crowley, \\ Kenneth J. Kimball, Brian J. Lashway
}

This report was prepared as an account of work sponsored by the United States Government. Neither the United States, nor the United States Department of Energy, nor any of their employees, nor any of their contractors, subcontractors, or their employees, makes any warranty, express or implied, or assumes any legal liability or responsibility for the accuracy, completeness or usefulness of any information, apparatus, product or process disclosed, or represents that its use would not infringe privately owned rights. 
The Use of Electrochemical Techniques to Characterize Wet Steam Environments

\author{
Bruce W. Bussert, John A. Crowley, Kenneth J. Kimball, Brian J. Lashway \\ Lockheed Martin, Schenectady, NY 12301
}

\begin{abstract}
The composition of a steam phase in equilibrium with a water phase at high temperature is remarkably affected by the varying capabilities of the water phase constituents to partition into the steam. Ionic impurities (sodium, chloride, sulfate, etc.) tend to remain in the water phase, while weakly ionic or gaseous species (oxygen) partition into the steam. Analysis of the water phase can provide misleading results concerning the steam phase composition or environment. This paper describes efforts that were made to use novel electrochemical probes and sampling techniques to directly characterize a wet steam phase environment in equilibrium with high temperature water.

Probes were designed to make electrochemical measurements in the thin film of water existing on exposed surfaces in steam over a water phase. Some of these probes were referenced against a conventional high temperature electrode located in the water phase. Others used two different materials (typically tungsten and platinum) to make measurements without a true reference electrode.

The novel probes were also deployed in a steam space removed from the water phase. It was necessary to construct a reservoir and an external, air-cooled condenser to automatically keep the reservoir full of condensed steam. Conventional reference and working electrodes were placed in the water phase of the reservoir and the novel probes protruded into the vapor space above it.

Finally, water phase probes (both reference and working electrodes) were added to the hot condensed steam in the external condenser. Since the condensing action collapsed the volatiles back into the water phase, these electrodes proved to be extremely sensitive at detecting oxygen, which is one of the species of highest concern in high temperature power systems.

Although the novel steam phase probes provided encouraging initial results, the tendency for tungsten to completely corrode away in the steam phase limited their usefulness. However, the conventional water phase electrodes, installed both in the reservoir and in the external condensing coil, provided useful data showing the adverse impact of oxygen and carbon dioxide on the REDOX potential and high temperature $p H$, respectively.
\end{abstract}

\section{INTRODUCTION}

Steam plant equipment can be particularly susceptible to corrosive attack in wet steam. Steam turbine disc cracking 1,2 and erosion-corrosion in steam turbine crossaround and extraction pipes ${ }^{3}$ are two notable examples of corrosion problems which have occurred in wet steam. Although the corrosion involved in these instances is due to the presence of a liquid phase, the simultaneous existence of a vapor phase in equilibrium with the corroding medium affects both the $\mathrm{pH}$ and oxidizing conditions. For instance, turbine crossaround and extraction piping erosion-corrosion has some dependence on $\mathrm{pH}$, with higher $\mathrm{pH}$ levels tending to mitigate the attack. Condensate $\mathrm{pH}$ is controlled by adding one of several amines to the feedwater. The ability of a given amine to mitigate erosion-corrosion in wet steam is not simply a function of the condensate $\mathrm{pH}$ or even the high temperature $\mathrm{pH}$, but also depends on how the amine partitions between the steam and vapor phases at the point in the cycle where the attack occurs. Ammonia, which partitions predominantly into the steam phase, does a poor job of raising the $\mathrm{pH}$ at the point of attack and is ineffective at preventing erosion corrosion in susceptible materials. However, morpholine and similar amines which partition more favorably into the liquid phase are also more effective at reducing the attack ${ }^{4}$.

Low alloy, high strength materials such as quenched and tempered AISI 4140 steel are particularly susceptible to stress corrosion cracking in oxygenated high temperature water. Unlike the fairly clean turbine disk materials mentioned earlier, AISI 4140 contains sulfur, present as manganese sulfide inclusions. Under oxidizing conditions in high temperature water, the sulfides can dissolve and accumulate at the crack tip to form an acidic sulfide environment which can cause rapid cracking. This phenomenon is often called environmentally assisted cracking (EAC) and is usually associated with dramatic enhancements in fatigue growth rates of lower strength materials 5 . However, growth rates in quenched and tempered AISI 4140 steel as high as $3 \times 10^{-8} \mathrm{~m} / \mathrm{s}$ under 
static load conditions have been observed in tests in oxygenated high temperature water and steam in our laboratory. This susceptibility limits the general usefulness of highly stressed 4140 steels in high temperature water systems in which oxidizing conditions are occasionally expected. However, it is an ideal material for laboratory investigations of the potential impact of oxygen on similar but less susceptible water and steam phase materials (for instance, pressure vessel steels and welds) in high temperature systems, with particular emphasis on components or surfaces which are in saturated or wet steam.

Characterizing the environment on a component or surface in wet steam presents an interesting challenge. Sampling the steam and cooling it to room temperature allows it to be analyzed, but the high temperature speciation and particularly the distribution of those species between the high temperature liquid and vapor phases is lost. Oxygen and other non-ionic substances partition heavily to the vapor phase and thus will disproportionately influence the composition of a condensed steam sample. In saturated or wet steam, the thin film of water on a component or surface is responsible for the actual corrosive attack, and that film would have much lower oxygen, for instance, than a condensed steam sample would indicate. A program like MULTEQ or OLI could be used to predict the high temperature liquid and vapor phases, but since these programs are developed solely from thermodynamic calculations, the impact of kinetic phenomena would be lost.

This paper describes work performed to directly characterize the environment on a component or surface in saturated or wet steam. Two methods, both involving passive electrochemical techniques, were used. In one, several novel steam phase sensors were developed to make electrochemical measurements in the thin film of water which naturally exists on a surface in wet or saturated steam. In the other, some of the steam was condensed at temperature and pressure, and allowed to come to equilibrium with the steam. Conventional liquid phase electrochemical probes were then used to characterize the liquid phase in equilibrium with the vapor at temperature and pressure. As part of both methods, in-situ monitored AISI 4140 compact tension specimens were used to correlate the measured electrochemical conditions with the potential for stress corrosion cracking.

\section{EXPERIMENTAL}

Experiments were conducted in two facilities. Preliminary studies were performed in an autoclave featuring two phase operation with the liquid phase recirculated. Later, an apparatus was inserted into the steam drum of a test boiler to make similar measurements.

\section{II.A. Laboratory Autoclave Experiments}

The autoclave experiments were performed in an 8 liter autoclave. The Carpenter 20 autoclave featured a train of four small $(0.4 \mathrm{~T}, 2.46 \mathrm{~cm}$ by $2.54 \mathrm{~cm}$ by $1.02 \mathrm{~cm}$ thick) compact tension specimens of AISI 4140 (see Table 1), which were precracked to $\mathrm{a} / \mathrm{w}=0.5$ and externally loaded to an initial stress intensity factor of $33 \mathrm{MPa} / \mathrm{m}$. The liquid phase of the autoclave was cooled and recirculated through an Orbisphere oxygen sensor. Oxygenated makeup water could be added as desired from a feed tank overpressurized with an oxygen/nitrogen mixture. When oxygenated water from the feed tank was added, an equal amount was withdrawn from the autoclave at the same rate, so as to maintain a constant level in the autoclave. The level in the autoclave was tracked using a series of platinum conductivity probes spaced at $\sim 1 \mathrm{~cm}$ intervals near the desired level, which was chosen so that two specimens were in the steam phase and two were in the water phase. Testing was typically performed at $250^{\circ} \mathrm{C}$.

Table 1

Composition of AISI 4140 Used for Compact Tension Specimens (Wt. Percents)

\begin{tabular}{|l|l|l|l|l|l|l|l|}
\hline $\mathrm{C}$ & $\mathrm{C}_{\mathrm{T}}$ & $\mathrm{Mn}$ & $\mathrm{Ni}$ & $\mathrm{P}$ & $\mathrm{Mo}$ & $\mathrm{Si}$ & $\mathrm{S}$ \\
\hline .41 & .99 & .88 & .06 & .017 & .18 & .27 & .026 \\
\hline \multicolumn{3}{|c|}{$\begin{array}{c}\text {.02\% offset yield: } \\
762 \mathrm{Mpa}\end{array}$} & \multicolumn{3}{c|}{ Ultimate Tensile Strength: } \\
\hline \multicolumn{3}{|c|}{$965 \mathrm{MPa}$} \\
\hline
\end{tabular}

A blind palladium tube was inserted into the steam space of the autoclave and continually flushed with a slow flow of argon to limit hydrogen buildup in the vapor phase.

Each compact tension specimen was fitted with six wires so its crack length could be monitored using the reversing DC potential drop method. The specimens were electrically isolated from the load train with zirconia bushings which allowed the electrochemical potential of each specimen to be monitored. The autoclave also featured several thermocouples, standard electrochemical probes (platinum wire, tungsten wire, and carbon steel wire), one or two external, pressure balanced $\mathrm{Ag} / \mathrm{AgCl}$ reference electrodes, and a series of experimental probes designed to make electrochemical measurements in the steam phase.

\section{II.B. Test Loop Monitoring}

A special instrumentation package was inserted into the steam drum of a test loop boiler to confirm the laboratory results on a larger scale. The key features of the package included a tray to hold condensed steam and an external cooling coil to keep the tray overflowing with condensed steam. The flow rate of condensate from the coil was estimated at about half the volume of the liquid tray per hour. The tray was located in a low steam velocity region somewhat above the normal water level in the boiler, but at 
times the level was higher than the tray which flooded the tray with a phosphate based boilerwater chemistry.

Two $0.4 \mathrm{~T} 4140 \mathrm{CT}$ specimens were situated in and above the tray, respectively, and were instrumented with potential drop leads. These specimens were loaded to 40 $\mathrm{MPa} \sqrt{\mathrm{m}}_{\mathrm{m}}$ by fairly compliant Alloy X-750 rings which were approximately $13 \mathrm{~cm}$ in outer diameter, $4 \mathrm{~cm}$ wide, and 0.6 $\mathrm{cm}$ thick. Tungsten, platinum, and high temperature reference electrodes (similar to those used in the laboratory

\section{II.C. Novel Steam Phase Electrochemical Probes}

The compact tension specimens which were situated above the water level in the autoclave testing described above provided reasonable and responsive electrochemical potentials when read against a conventional high temperature electrode located in the water phase (see Figure 1).

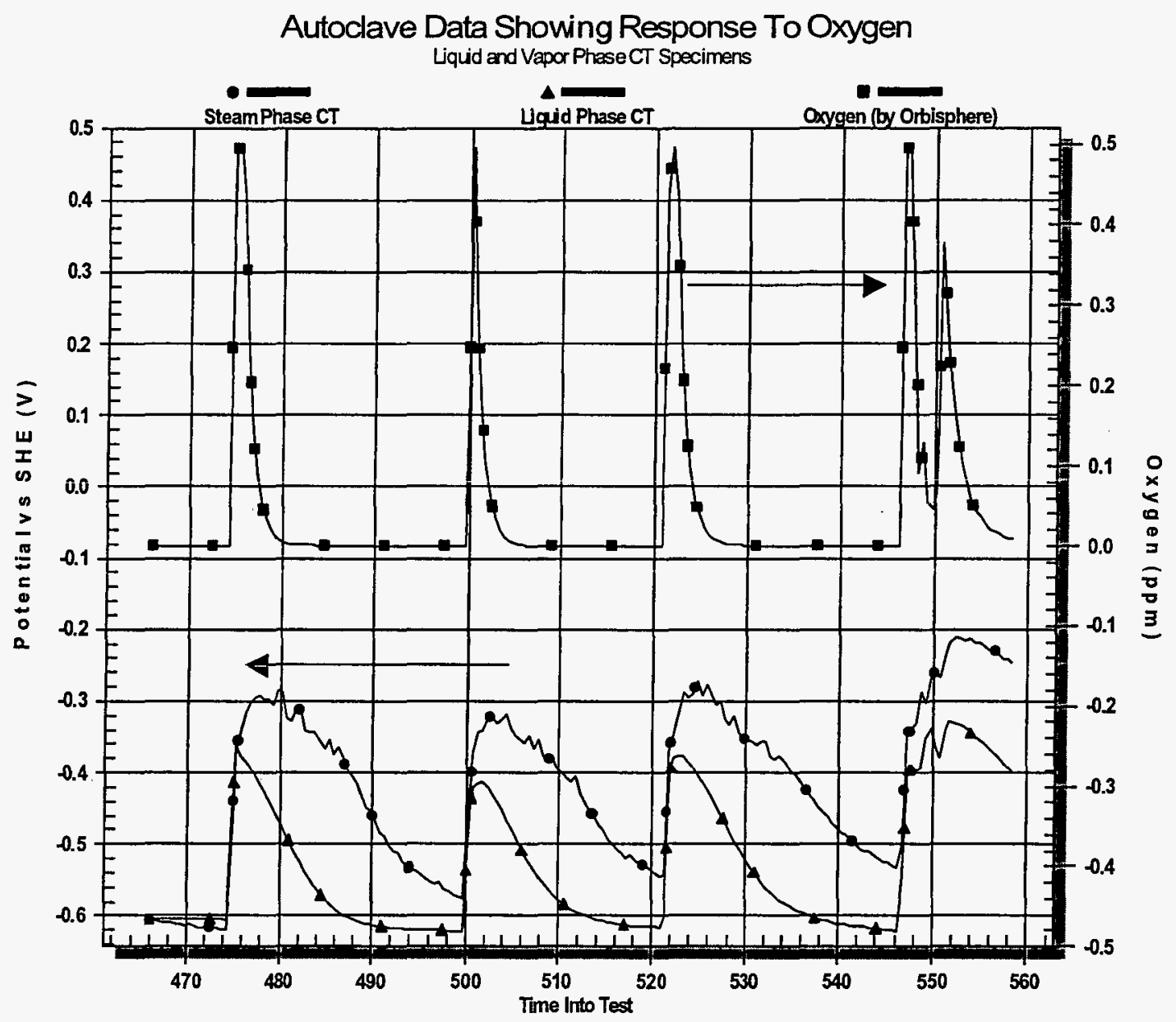

Fig. 1. Potentials of liquid and vapor phase AISI 4140 compact tension specimens in response to oxygen additions

test) were situated in the tray. Novel steam phase electrochemical probes (see description below) were installed such that they protruded from the water in the tray into the steam above the tray.

Finally, simple wire electrodes (platinum, tungsten, and carbon steel) and a reference electrode were installed into the outlet of the cooling coil, upstream of where it emptied back into the tray. By limiting how many coils of the external condenser were below the liquid level, it was possible to minimize the amount of subcooling which was present at the probe locations in the coil. Those probes typically ran $40-50^{\circ} \mathrm{C}$ cooler than the probes inside the steam drum.
Not only did the vapor phase CT specimen potentials appear reasonable, they also peaked higher and decayed more slowly in response to oxygen. These observations were lent additional credence by the observation that the CT specimen just above the liquid line was repeatedly the first to crack in response to the oxygen additions.

The authors do not believe that the electrochemical potentials measured on the "vapor" specimens and probes described below involve any true vapor phase electrochemistry. It is suspected that the specimens and probes were connected to the liquid phase by a thin film of water which provided an ion conducting path and allowed pseudo-vapor phase electrochemical measurements to be 
made. Note that these measurements would be expected to have errors due to liquid junction potentials and perhaps IR currents. However, the readings appeared to provide useful qualitative information about the environment on a part or surface located above the water line in saturated steam. Therefore, several probes were designed using the idea that a thin film of water could conduct enough ions to allow electrochemical potentials to be measured on a probe which protruded into the vapor phase.

\section{II.C.1. Double Coupon Probe}

The first attempt at making a vapor probe drew on the experience with the potential data from the train of compact tension specimens shown in Figure 1. This probe was simply two coupons of carbon steel approximately $1.25 \mathrm{~cm}$ by $8 \mathrm{~cm}$ by $1.25 \mathrm{~mm}$ thick which were bolted together with Teflon bushings to keep them electrically isolated. A carbon steel lead wire was welded to each coupon. These leads were covered with a continuous length of heat shrink probe after test. The liquid interface is clearly indicated on the bottom coupon.

\section{II.C.2. Helical Coil}

A helical coil was constructed consisting of a platinum wire and a tungsten wire (both approximately $.5 \mathrm{~mm}$ in diameter) wound around a zirconia tube which was machined with spiral grooves to hold the wires in place. In test, the helical coil probe was vertically oriented with its bottom in the liquid and the top with the exposed wires in the vapor phase.

Except for the exposed sensing portion, the wires were each coated with a continuous length of heat-shrink PFA or PTFE Teflon tubing. The wires exited the autoclave through a Teflon packed Conax fitting. In the final design, only the last two complete turns of the wires were actually bare. The helical probe provided two kinds of measurements. Either of the wires could be measured against a conventional high temperature electrode in the

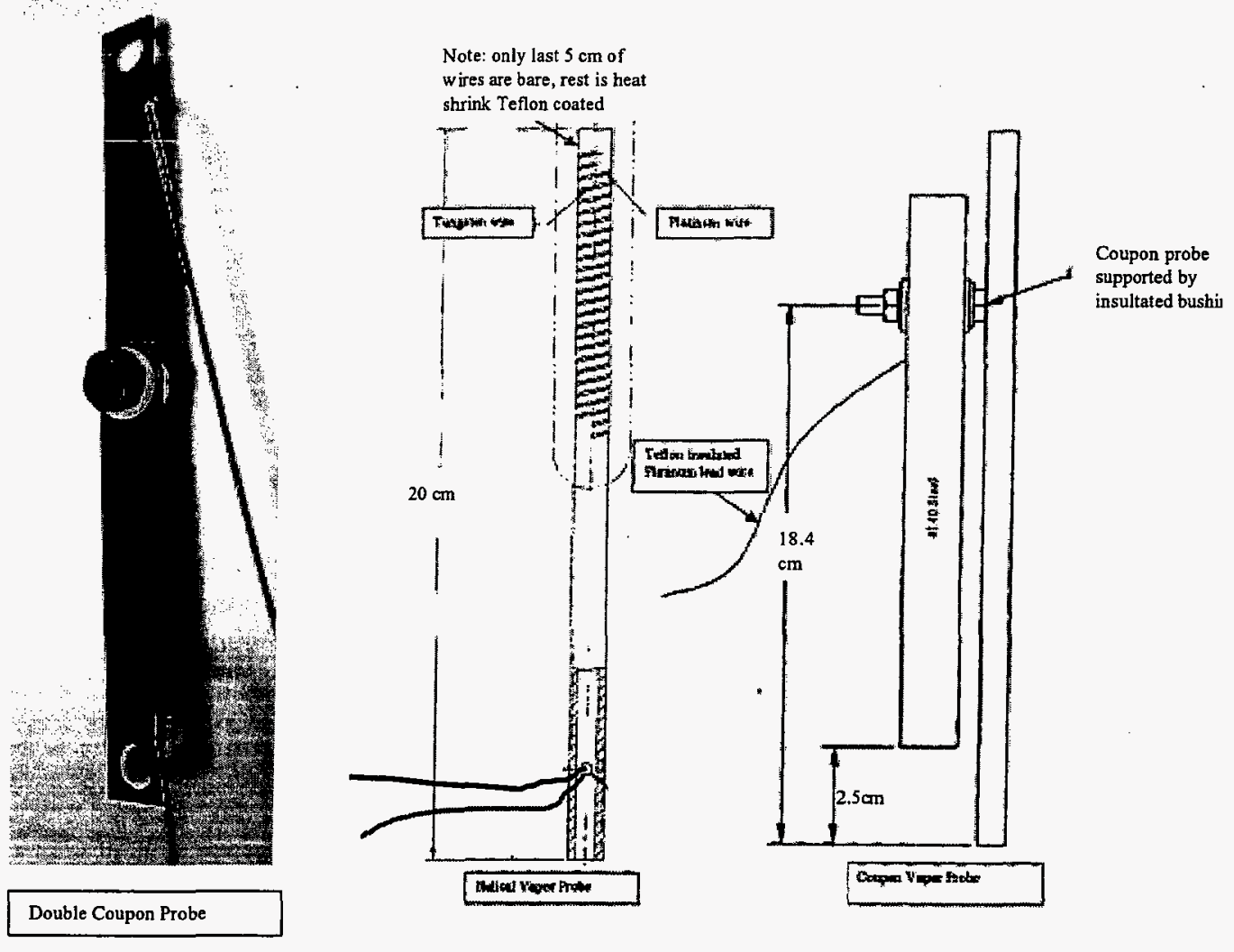

Fig. 2. Novel steam phase electrochemical probes.

Teflon tubing and passed through Teflon packed Conax fittings to exit the autoclave. The double coupon probe was oriented vertically with the bottom coupon partly in the water and partly out, and the top coupon entirely out of the water. Figure 2 shows a photograph of the double coupon liquid phase to provide a $\mathrm{pH}$ (tungsten), or electrochemical potential (platinum). Alternately, the wires could be read against each other to provide a $\mathrm{pH}$-independent REDOX potential. In practice, all three measurements were made.

An earlier design of helical probe was situated in one phase only (vapor or liquid), and used carbon steel and 
tungsten wires. When this design was placed in the vapor phase only relative measurements (carbon steel versus tungsten) could be made.

\section{II.C.3. Coupon Probe}

The thermal mass of a part located in the steam phase might affect how it wets and would respond to oxygen (on heating up, for instance, such a surface might have enhanced condensation). Therefore, the third probe constructed was a fairly massive $2.5 \times 2.5 \times 20 \mathrm{~cm}$ steel coupon which simply protruded from the liquid into the vapor phase. Unlike the other probes, the design of the coupon probe made no attempt to isolate that part which protruded into the steam phase. A platinum wire was welded to the coupon probe to allow its measurement. The platinum wire was again covered with a continuous length of heat shrink Teflon tubing. Both the wire and the mounting stud (see Figure 2) were located above the liquid level when the coupon probe was installed.

\section{RESULTS OF AUTOCLAVE TESTING}

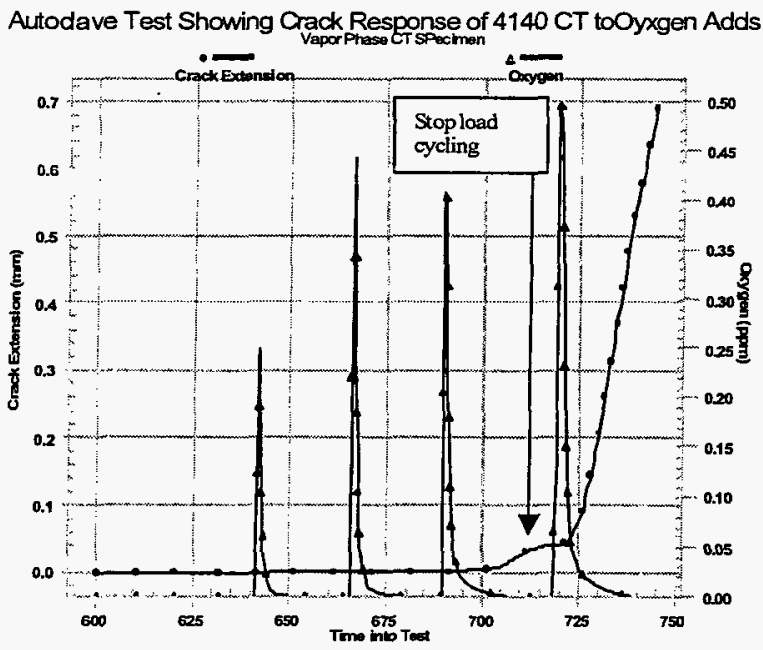

Figure $3 \mathrm{a}$ presents the cracking response of a 4140 0.4T $\mathrm{CT}\left(1 \mathrm{~cm}\right.$ thick) to repeated oxygen additions at $250^{\circ} \mathrm{C}$. The water phase in the autoclave contained about $10 \mathrm{ppm}$ phosphate solution. Although four identical specimens were present in the autoclave as described earlier, only the data from the one just above the water line (the only one that cracked) is shown. This specimen was loaded to $33 \mathrm{MPa} / \mathrm{m}$ with a $30 \%$ unload once every three hours until the point shown on the graph, at which time the unload cycle was stopped. Following the fourth oxygen addition, the crack began growing at a rate of $25 \mathrm{~cm} / \mathrm{yr}$. (In similar tests in the laboratory autoclave, rates up to $100 \mathrm{~cm} / \mathrm{yr}$ have been observed under these same conditions.) . Note that the oxygen plotted on Figure $3 \mathrm{a}$ is measured in the liquid phase. Oxygen decayed naturally as a result of reaction with the autoclave and the specimens in the autoclave.

Figure $3 \mathrm{~b}$ presents data from the double coupon probe taken during this same period of time. The potential of each half of the double coupon is shown, along with a single coupon of the same dimensions which was kept entirely in the liquid phase.

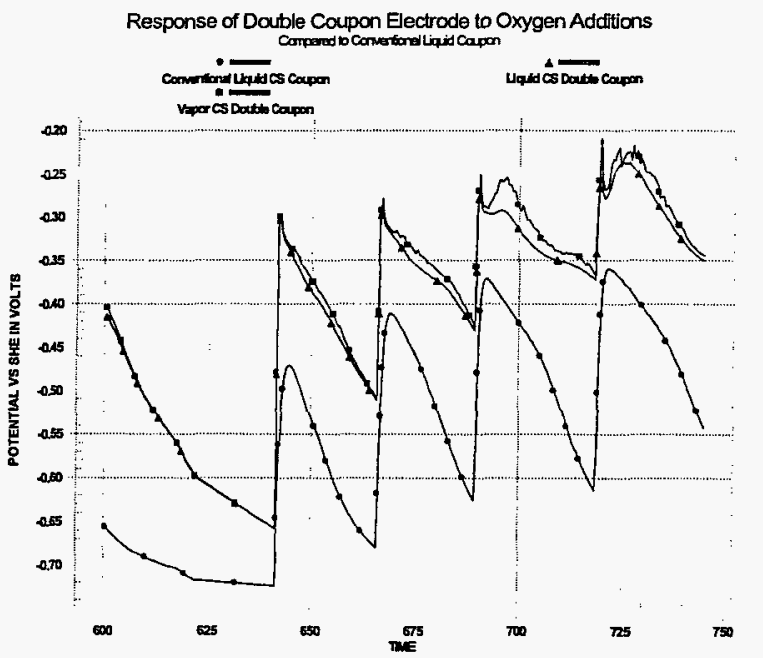

Fig. 3a (left) Response of crack in AISI 4140 compact tension specimen to oxygen additions. Fig. 3b(right) response of double coupon probe to these same additions.

Surprisingly, both halves of the double coupon probe, one entirely in the vapor phase and the other partially in the vapor phase, behaved similarly, and gave more anodic potentials with a longer decay time than the conventional probe which was located entirely in the liquid phase. It was this observation which eventually led to the design for the larger coupon probe described earlier, since it didn't seem to matter if the vapor portion of the probe was electrically isolated from the portion which was in the liquid phase.

Figure $3 \mathrm{c}$ shows the behavior of two helical coil probes, in the vapor and liquid phases, respectively, during the same time period shown in Figures $3 a$ and $3 b$. These helical probes are of the early design which featured carbon steel and tungsten wires. Only the relative (i.e., carbon steel versus tungsten) potentials were measured in this test. Again, the vapor phase probe readings indicate a more oxidizing condition. 


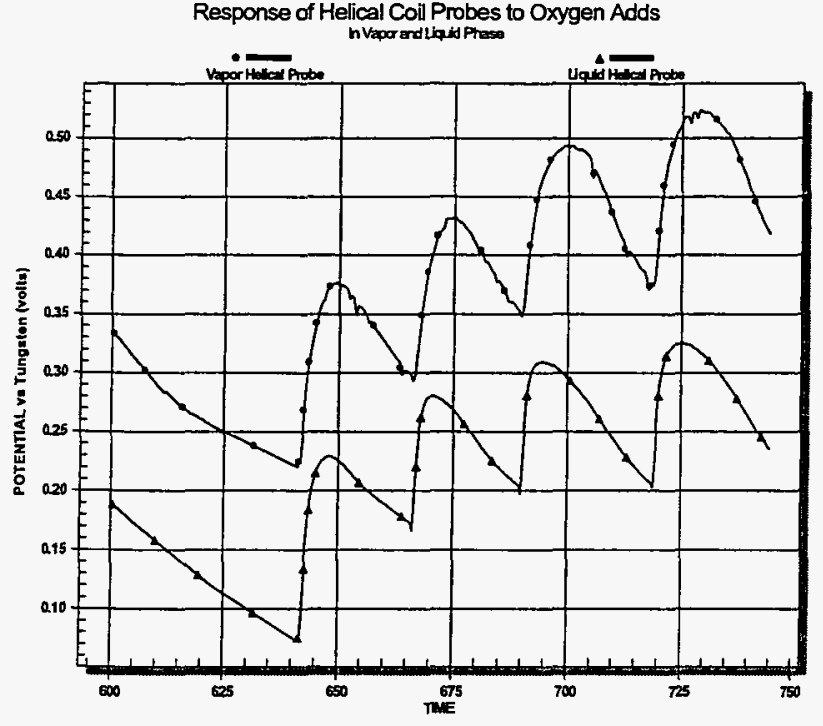

Fig. 3c Response of helical coil probes to the same oxygen additions shown in Figs. $3 a$ and $3 b$.

As stated earlier, the final design of the helical probe used platinum and tungsten instead of carbon steel and tungsten wires. Figure 4 shows the response of this helical probe to oxygen.

Figure 4

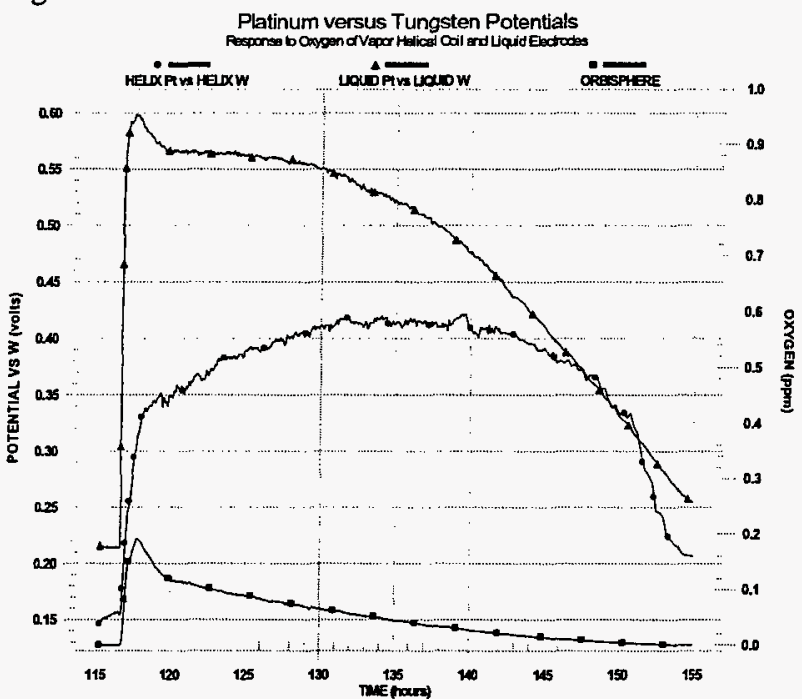

Fig. 4. Response of platinum versus tungsten helical coil probe to oxygen addition.

The relative (i.e., platinum versus tungsten) readings are plotted and compared with platinum versus tungsten readings in the liquid phase (which was a phosphate solution of about $175 \mathrm{ppm}$ ). The behavior of the platinumtungsten readings is dramatically different from the carbon steel-tungsten readings shown in Figure 3. Reasons for this difference are discussed later.
Finally, Figure 5 shows the response of the helical probe to a change in $\mathrm{pH}$ independent of the liquid phase chemistry. The data shows the response of a tungsten wire in the liquid phase and a tungsten wire on a vapor phase helical probe to a change in liquid phase chemistry from 175 ppm phosphate plus $10 \mathrm{ppm}$ morpholine to $175 \mathrm{ppm}$ phosphate plus $100 \mathrm{ppm}$ morpholine. According to MULTEQ, this change should have virtually no effect on the liquid phase $\mathrm{pH}$, which is dominated by the phosphate. However, the $\mathrm{pH}$ of water in equilibrium with the vapor phase (i.e., minus the phosphate) is expected to rise by about $0.5 \mathrm{pH}$ units. Figure 5 shows that the vapor helical tungsten wire did correctly sense the change in $\mathrm{pH}$ due to the increase in morpholine.

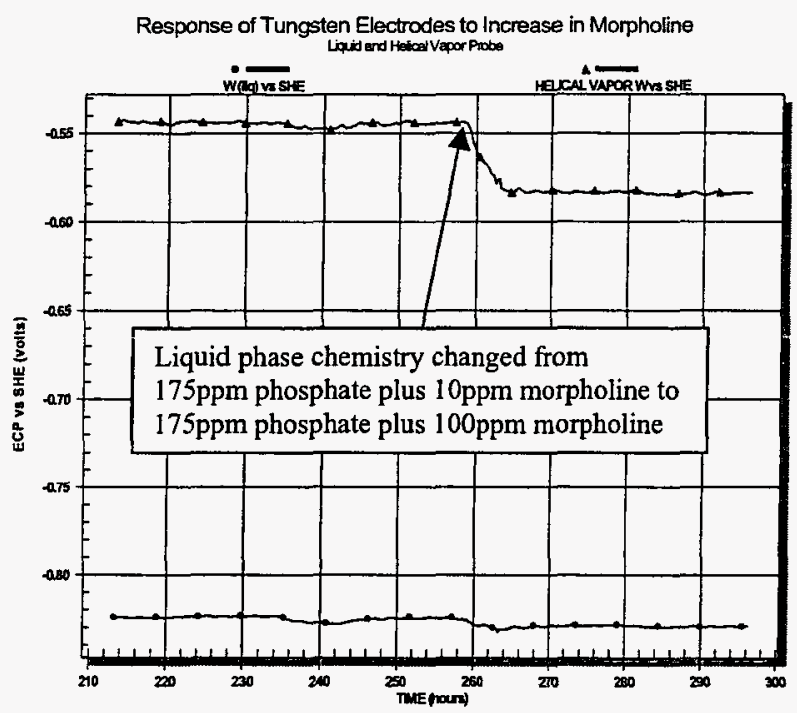

Fig. 5. Response of tungsten electrodes (one of which was part of a helical probe electrode) to morpholine addition.

\section{RESULTS OF TEST LOOP EXPERIMENTS}

As described earlier, a water tray was installed in the steam drum of a boiler in a large test loop. The original idea for the tray was to simply serve as a pool of water in which to install several of the vapor phase probes which were developed during the benchtop autoclave testing sequence. However, in addition to the vapor phase probes, a set of conventional probes was also installed entirely submersed in the tray itself, and a second set was installed in the outlet of the external condensing coil which kept the tray overflowing with water.

The vapor probes in the test loop boiler did respond to oxygen, but not as strongly as had been observed during autoclave testing. In addition, the vapor phase probes proved to be very noisy, responding to, for instance, very small amounts of superheat which developed as the temperature in the test loop varied. In a way, this validated the original design of the probes, which depended on a 
liquid film to provide a conducting bridge from the probe located in steam to a reference probe located in water. With small amounts of superheat $\left(1-2^{\circ} \mathrm{C}\right)$, the probes apparently dried out and began to give erroneous data.

The conventional probes located in the water tray itself and also in the outlet of the external condensing coil provided very useful data. In combination with the in-situ cracking data from the ring loaded $\mathrm{CT}$ specimens, these probes eventually provided a much clearer definition of the steam environment and the impact of oxygen events on cracking of the ring loaded CT specimens.

\section{IV.A. Characterization of Startup Conditions}

The test boiler probes identified the period just after a startup as being the most vulnerable time to oxygen. The boiler steam drum contained air prior to heatup. Although some of this air was bled out by venting at low temperature, a significant portion remained behind and subsequently had a major impact on the steam environment as sensed by the probes and by the compact tension specimens.

This can be shown by plotting the probe data as a Poubaix diagram, i.e., with the high temperature potential plotted against the indicated high temperature $\mathrm{pH}$. The tungsten electrode readings (from the water in the tray) versus the high temperature silver/silver chloride electrode were used to calculate a high temperature $\mathrm{pH}$. Platinum readings (again in the water in the tray) versus the same high temperature electrode were converted to the standard hydrogen scale. The resulting data is shown on Figure 6.

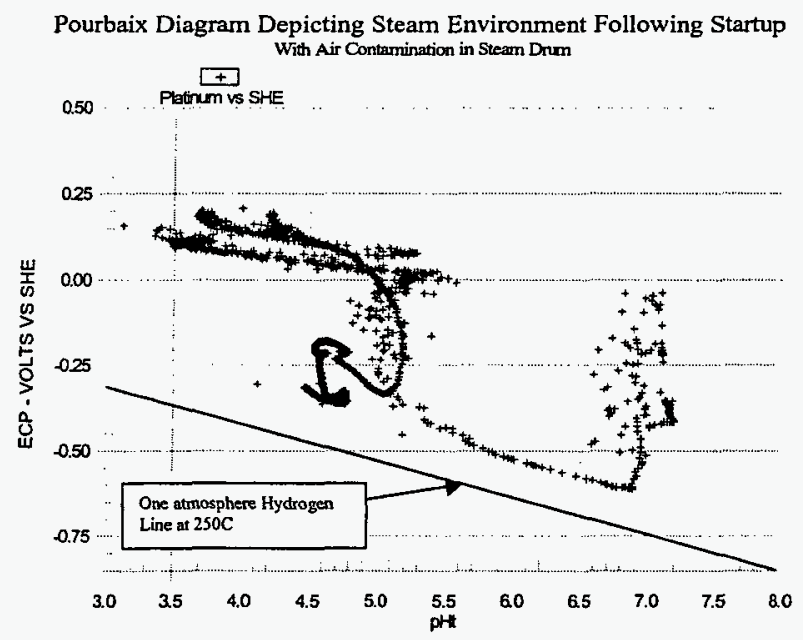

Fig.6. Pourbaix diagram depicting steam environment following startup with air contamination in steam drum.

For this plot, only data above $200^{\circ} \mathrm{C}$ are plotted. The data span a range of temperatures from $200^{\circ} \mathrm{C}$ to approximately $250^{\circ} \mathrm{C}$ and cover a period of 48 hours during which the process boiler was at temperature but was not generating steam. For convenience all the data are plotted on the same chart which also shows a one atmosphere hydrogen line for $250^{\circ} \mathrm{C}$.

This startup caused a cracking event on the ring loaded $4140 \mathrm{CT}$ specimen located in the steam above the tray. The crack started growing about 12 hours after the temperature exceeded $200^{\circ} \mathrm{C}$, and grew for about 9 hours at a rate of 1.6 $\times 10^{-8} \mathrm{~m} / \mathrm{s}$.

The $\mathrm{pH}$ extremes plotted on Figure 6 merit some explanation. As explained earlier, the tray was located at a point in the boiler drum which was periodically flooded by boilerwater chemistry containing a phosphate chemistry. This caused the high temperature $\mathrm{pH}$ to peak at over 7.0 The indicated $\mathrm{pH}$ also dipped as low as 3.5 during this period. While there is reason to believe that the $\mathrm{pH}$ was low (the trapped air would also contain carbon dioxide), the tungsten electrodes have also exhibited some sensitivity to oxygen, which would falsely indicate a lower $\mathrm{pH}$.

In contrast to the startup data depicted in Figure 6, the test boiler was later heated up with an inert gas (nitrogen) instead of air in the steam drum. Figure 7 shows the corresponding data from that heatup. As before, only data over $200^{\circ} \mathrm{C}$ are shown, the data represent 48 hours, and the Pourbaix diagram is plotted for $250^{\circ} \mathrm{C}$ even though the data points represent a range of temperatures.

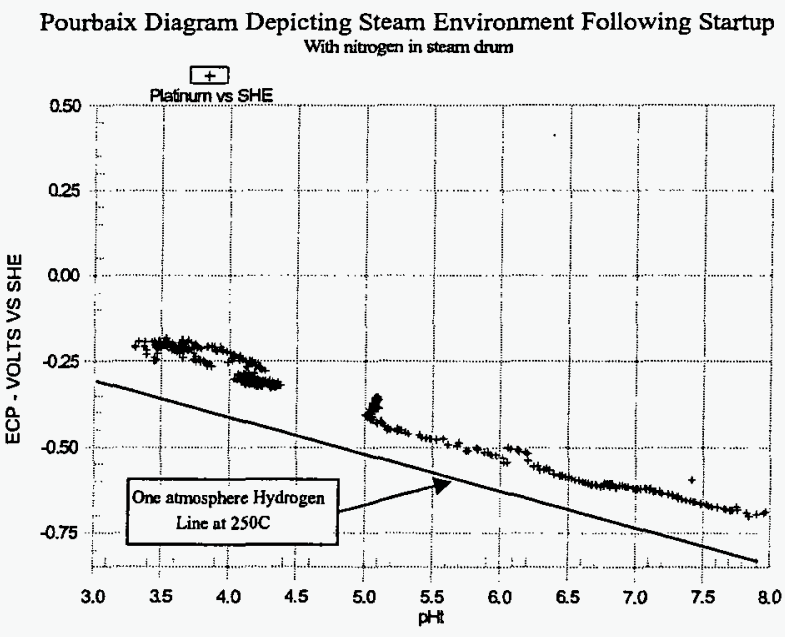

Fig. 7. Pourbaix diagram depicting steam environment following startup with nitrogen in steam drum

There was no cracking associated with this startup. Very low $\mathrm{pH}$ values are still observed, but the oxidizing conditions are absent. The cause of the low $\mathrm{pH}$ is uncertain, although it is possible that organic acids are responsible. 


\section{IV.B. Characterization of Operating Conditions}

Figure 8 shows potential data from a several day period when oxygen was periodically introduced to the system during operation. On Figure 8 , the platinum potentials from the tray and the condensing coil are plotted against time. The oxygen shows up in the condensing coil but arguably does not result in any change in the platinum electrode in the tray. Figure 9 shows how several of the novel steam space electrodes (extending from the tray into the steam above the tray) responded to these same events. The large coupon probe did not react at all to the oxygen spikes, but those spikes were about two orders of magnitude lower than the oxygen spikes introduced during the laboratory tests. The helical coil probe relative measurement (i.e., Platinum vs tungsten) did react but the response is much smaller than was seen in the condensing coil probes.

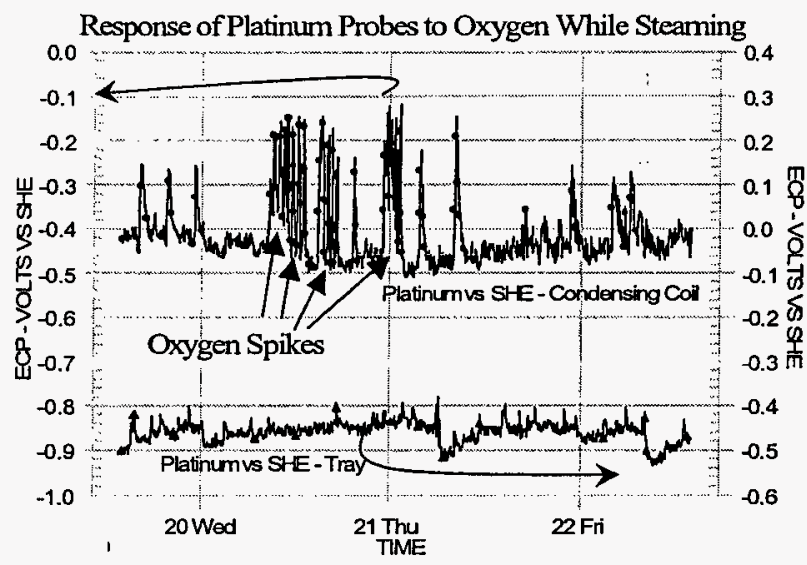

Fig. 8. Response of platinum probes to oxygen additions while steaming.

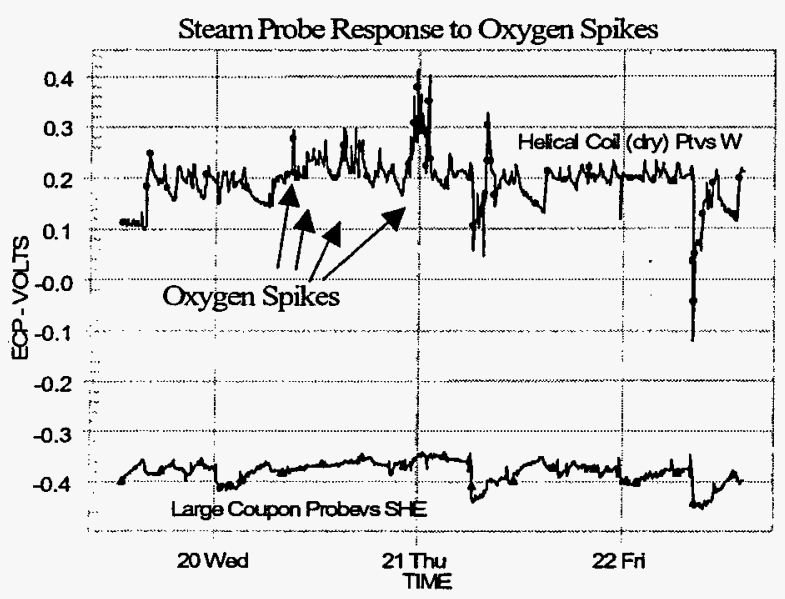

Fig. 9. Response of novel steam probes to same oxygen additions shown in Figure 8.

Finally, Figures 10 and 11 present the $\mathrm{pH}$ and potential data for the exact same periods shown in Figures 8 and 9 on a Pourbaix type diagram with the one atmosphere hydrogen line at $250^{\circ} \mathrm{C}$ shown. The platinum and $\mathrm{pH}$ in the tray (Fig. 10 ) and condensing coil (Fig. 11) are plotted. Note that the condensing coil probe location is about $50^{\circ} \mathrm{C}$ subcooled relative to the tray and saturated steam. The $\mathrm{pH}$ and potential vs SHE values for the condensing coil probe have taken the actual temperatures into account, but the $250^{\circ} \mathrm{C}$ line is shown for common comparison.

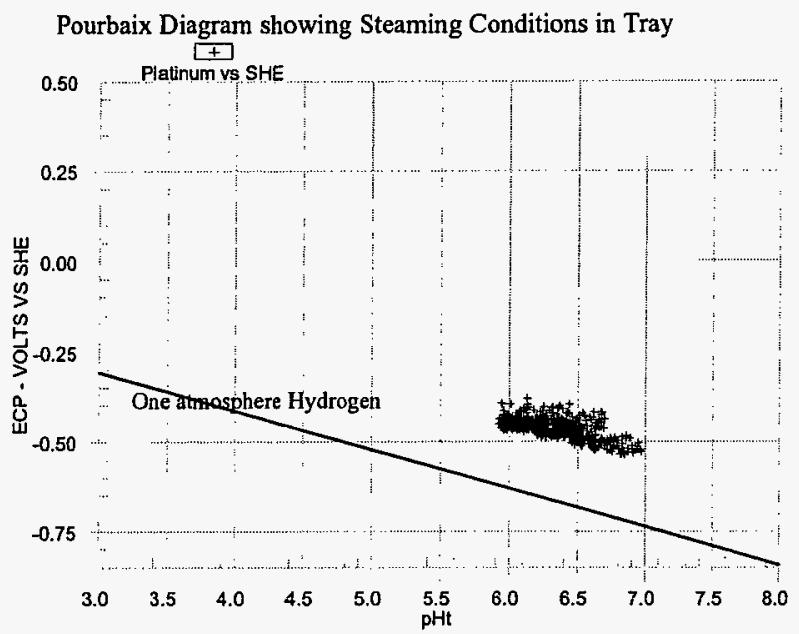

Fig. 10. Pourbaix type diagram describing the tray environment during the time period shown in Fig 8.

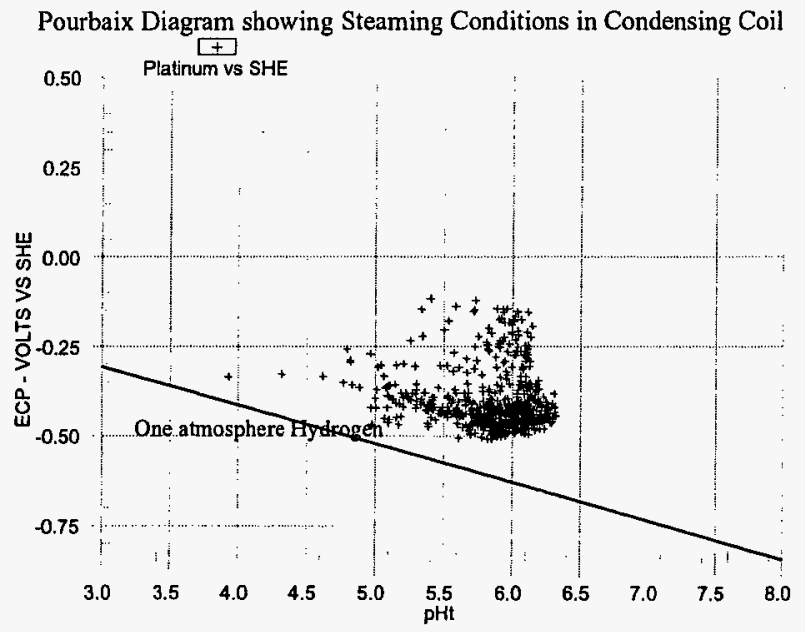

Fig. 11. Pourbaix type diagram describing the condensing coil environment during the time period shown in Fig. 8.

\section{DISCUSSION}

In the test loop, the data from the novel vapor probes proved almost unusable, since the probes were very noisy. The thin tungsten wires used in the helical probes also tended to completely dissolve away in a few months. 
In the more carefully controlled autoclave tests, the vapor probes appeared to give reasonable results. However, some of those results seem to conflict. For instance, the earlier design of the helical probe which used carbon steel and tungsten wires indicated that the vapor phase was more oxidizing, while the later version which used platinum and tungsten wires showed the opposite, if anything. A possible explanation follows.

Oxygen in the liquid phase partitions into the vapor according to Henry's law. According to MULTEQ, the "distribution" coefficient for oxygen at $250^{\circ} \mathrm{C}$ is about 720 , so when $0.5 \mathrm{ppm}$ oxygen is measured in the liquid phase, the vapor phase contains much more. The vapor probes, as described earlier, don't really sense the oxygen in the vapor phase directly, but the oxygen in a liquid film which is in equilibrium with the vapor phase. The same distribution coefficient works backwards and thus the film on the vapor probe is expected to also have $0.5 \mathrm{ppm}$ oxygen.

The potential measured on a carbon steel wire is not a true electrochemical potential, but is more properly termed a corrosion or mixed potential, since carbon steel actively corrodes (oxidizes) in high temperature water with oxygen. This process results in a gradient in the oxygen level near the surface of the carbon steel (the Nernst diffusion layer). In liquid systems, velocity and particularly turbulence can act to bring oxygen closer to the corroding surface and thus can increase the corrosion potential significantly. This phenomenon has been described in detail by Macdonald ${ }^{6,7}$, who also has evaluated potentials of surfaces covered with a thin film of water ${ }^{8}$. Unfortunately, the latter work did not study the effect of varying the water film thickness (in his work, of a part in humid air), and perhaps correctly estimated the water film as being the same as the corrosion layer thickness.

The diffusion of oxygen through a thin film offers an explanation why the carbon steel/ tungsten helical probe sensed a more oxidizing environment in vapor compared to liquid when oxygen was added. The thin film of water on the vapor probe reduces the distance that oxygen has to diffuse to get to the metal/oxide interface. This increases the effective amount of oxygen at the surface, which in turn raises the corrosion potential.

This same phenomenon also explains why the platinum/tungsten helical coil behaved differently. Since platinum does not corrode, there is little or no oxygen gradient as the platinum surface is approached. Thus, it makes no difference whether the platinum electrode is immersed in liquid water or is exposed in the vapor covered with a thin film of water. In either case, the oxygen at the metal surface will be similar, and the half cell potential should also be similar. The fact that the platinum/tungsten vapor probe actually gave a smaller response to oxygen (see Figure 4) than was measured in liquid is due to the enhanced response of the tungsten electrode on the vapor probe to oxygen, possibly due to the same phenomenon described above for carbon steel. Figure 12 shows the absolute potentials (vs SHE) for the same platinum and tungsten wires over the same time period plotted in Figure 4 . The response of tungsten to oxygen is clearly enhanced on the vapor phase helical probe, which lessens the overall response as was plotted in Figure 4.

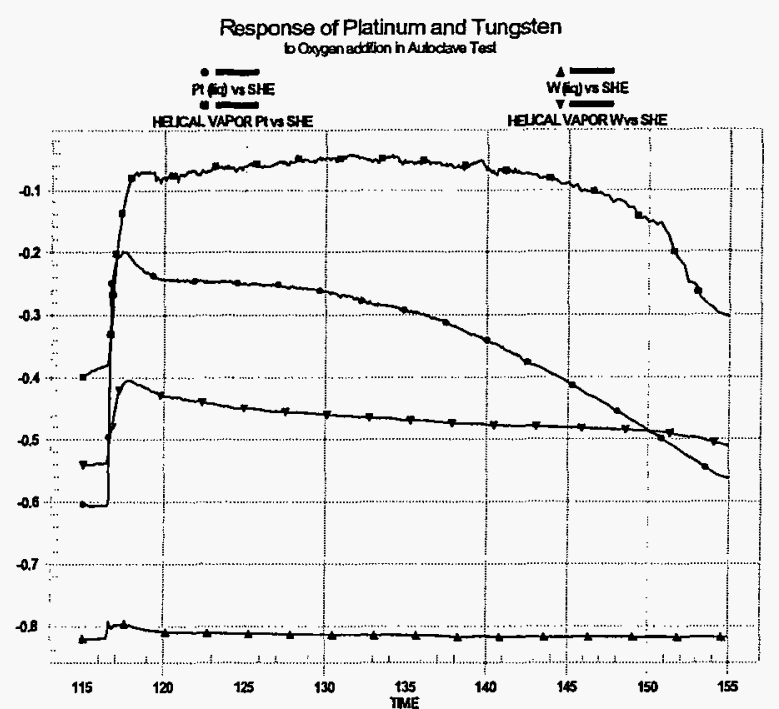

Fig. 12. Response of platinum and tungsten probes to oxygen additions in autoclave test (see also Fig. 4).

Figure 12 also shows additional information not shown in Figure 4. The difference in the potentials of the tungsten wires in the liquid and on the vapor probe implies that the high temperature $\mathrm{pH}$ of the film on the vapor probe is about $2 \mathrm{pH}$ units more acidic than the liquid in the autoclave, which contains phosphate. This difference in $\mathrm{pH}$ makes it harder to see the net effect of oxygen on the two sets of probes. By making a relative measure of the probes as was done on Figure 4 , the difference in $\mathrm{pH}$ is eliminated as a confounding factor.

Figure 8 shows that the probes located in the outlet of the condensing coil were much more sensitive to oxygen than either the probes in the liquid tray or the vapor probes installed above the liquid in the tray. The fairly rapid condensing action inside the coil apparently forced the volatile species like oxygen into a non-equilibrium condition which was maintained until the condensate flowed back into the tray, where it came to equilibrium with the vapor. While the non-equilibrium conditions in the condensing coil are not representative of the environment on the surface of a part in the steam phase, they do provide additional useful sensitivity for determining when oxygen upsets are occurring.

Unfortunately, the life of the probes in the condensing coil was about 2-3 months, after which they they became noisy, or in the case of the reference electrode, developed a large error. There was some evidence that an organic material, perhaps oil, had also condensed in the external condensing coil and had fouled the electrochemical probes at that location. 


\section{SUMMARY}

This paper has described two different methods to use electrochemistry to characterize the environment on a surface or component in saturated steam. The novel probes described herein attempted to make electrochemical measurements on the film of water which would naturally form on a part in saturated or wet steam. These probes had more success in carefully controlled autoclave experiments than in the large test loop, probably because the changing conditions in the large test loop often disrupted the water film on the probes. The second method of characterizing a wet steam environment involves condensing some of the steam at temperature and pressure, and letting this liquid phase come to equilibrium with the steam. Conditions in the condensed phase are then characterized with conventional electrochemical probes and high temperature $\mathrm{pH}$ sensors. This method proved to be fairly simple, reliable, and provided reasonable data.

Oxidizing, low $\mathrm{pH}$ conditions on steam phase surfaces are most likely to occur as a result of trapping air in a system prior to startup. Air or oxygen ingress during operation had a very minor impact on the conditions on those same surfaces. Although thin film kinetics may play a minor role in enhancing vapor phase oxidizing potentials, Henry's law plays a much more important role by keeping most of the oxygen in the vapor phase.

Finally, this work confirms the unsuitability of highly stressed components made of sulfur-bearing, high strength low alloy steels in steam environments where oxygen is occasionally expected.

\section{REFERENCES}

[1] LYLE, F.F.,JR., and BURGHARD, H.C., JR., "Cracking of Low Pressure Turbine Rotor Discs in U.S.Nuclear Power Plants", Material Performance, 21 ,11, p. 35 (1982).

[2] LYLE, F.F.,JR, and BURGHARD, H.C., JR., Steam Turbine Disc Cracking Experience, Vols 1-7, Palo Alto, California: Electric Power Research Institute NP-2429-LD, June 1982.

[3] DELP, G.A., ROBINSON, J.D., AND SEDLACK, M.T., "Erosion Corrosion in Nuclear Plant Steam Piping: Causes and Inspection Program Guidelines." NP-3944, Palo Alto, California: Electric Power Research Institute, April 1985.

[4] GERDAN, J.P., GREGOIRE, J., AND LACAILLE, L., "Erosion Corrosion in Wet Steam - Impacts of Variables and Possible Remedies", Water Chemistry and Corrosion in the Steam-Water Loops of Nuclear Power Stations. Seillac, France: Conference ADERP, March 1980.

[5] MOSHIER, W.C. AND JAMES, L.A. "The Effect of Potential on the High Temperature Fatigue Crack Growth Response of Low Alloy Steels II: Sulfide-Potential Interactions", Corrosion Science 41, 2, p 401 (1999).

[6] MACDONALD, D.D., "Viability of Hydrogen Water Chemistry for Protecting In-Vessel Components of Boiling Water Reactors", Corrosion 48, 3, p 194, (1992.)

[7] MACDONALD, D.D. , SONG, H., MAKELA, K., AND YOSHIDA, K., "Corrosion Potential Measurements on Type 304SS and Alloy 182 in Simulated BWR Environments", Corrosion 49,1, p. 8, (1993.).

[8]MACDONALD, D.D. AND URQUIDI-MACDONALD, M., "Thin-Layer Mixed-Potential Model for the Corrosion of High -Level Nuclear Waste Canisters", Corrosion 46,5, p 380, (1990). 